\title{
LAS CONCESIONES EN SERVICIOS DE TELECOMUNICACIONES
}

\section{Rafael Torres Morales}

Abogado. Profesor del curso de Derecho Comercial en la Universidad de Lima. Especialista en derecho de las telecomunicaciones.

\section{LEGISLACIÓN DE TELECOMUNICACIONES (MARCO NORMATIVO)}

\subsection{Texto Único Ordenado de la Ley de Telecomunicaciones}

on fecha 6 de mayo de 1993 fue publicado el Texto
Único Ordenado -TÚO- de la Ley de Telecomunicacio-
nes (norma basada en las disposiciones contenidas en el
decreto legislativo 702 -Normas que regulan la Promoción de
Inversión Privada en Telecomunicaciones-, sus modificatorias y
complementarias) -decreto supremo 013-93-CC-, que en su arti-
culo 3 estableció claramente el derecho de toda persona (natu-
ral o jurídica) a usar, y/o a prestar servicios de telecomunicacio-
nes, de acuerdo con los requerimientos establecidos por las dis-
posiciones que regulan la materia.

\subsection{Reglamento General de la Ley de Telecomunicaciones}

Por decreto supremo 06-94-TCC, de 18 de febrero de 1994, fue publicado el Reglamento General de la Ley de Telecomunicaciones, dispositivo que ha sufrido desde entonces una serie de 
modificaciones a través de los decretos supremos 15-97-MTC (de 11 de julio de 1997), 5-98-MTC (de 26 de marzo de 1998), 22-98-MTC (de 13 de agosto de 1998) y 002-99-MTC (de 21 de enero de 1999).

\subsubsection{Normatividad general}

La sección primera del Reglamento General de la Ley de Telecomunicaciones establece el marco legal que rige todos los servicios relativos al ámbito de las telecomunicaciones. El artículo 6 señala que los servicios de telecomunicaciones se prestan dentro de un régimen de libre competencia, lo cual quiere decir que el Estado promueve la actividad asociativa y empresarial y deja de lado todo aquello que pudiera limitarlas.

Artículo 6.- Los servicios de telecomunicaciones se prestan en un régimen de libre competencia...

Asimismo, el artículo 8 establece que tanto el acceso a la utilización como la prestación de los servicios de telecomunicaciones se encuentran enmarcados dentro del principio de no discriminación.

\section{LOS SERVICIOS DE TELECOMUNICACIONES}

De acuerdo con la Ley General de Telecomunicaciones y su reglamento, los servicios de telecomunicaciones son actividades destinadas, bajo responsabilidad de una persona natural o jurídica (sin distinción alguna en cuanto a la forma en que ésta se constituye), a posibilitar y ofrecer una modalidad específica de telelecomunicaciones.
El artículo 8 de la misma clasifica estos servicios en cuatro modalidades: portadores, teleservicios o servicios finales, servicios de difusión y servicios de valor añadido. De conformidad con ello, el artículo 122 del Reglamento de la Ley General de Telecomunicaciones señala que tanto los servicios portadores como los finales y de difusión de carácter público, se prestan bajo el régimen de concesión, quedando entendido, por consiguiente, que los servicios de valor añadido (aquellos que utilizan como soporte a los servicios portadores o finales, añadiendo alguna característica o facilidad al servicio que les sirve de base; por ejemplo: empresa cuyo giro se dedique a la prestación de servicios de acceso a internet, correo electrónico, entre otros) no requieren de la obtención de una concesión, bastando efectuar un trámite de inscripción en el Registro de Servicios de Valor Añadido, el mismo que actualmente se encuentra administrado por el Ministerio de Transportes y Comunicaciones (MTC).

\section{LAS CONCESIONES}

El artículo 47 del TÚO de la Ley de Telecomunicaciones define el término "concesión" como aquel acto jurídico mediante el cual el Estado cede a una persona natural o juridica ( $\sin$ distinción alguna) la potestad de prestar un servicio portador, final o de difusión con carácter público, acto que queda perfeccionado mediante contrato escrito aprobado por resolución del sector (Ministerio de Transporte, Comunicaciones, Vivienda y Construcción).

Artículo 47.- Llámese concesión al acto jurídico mediante el cual el Estado cede a 
una persona natural o jurídica la facultad de prestar un servicio portador, final o de difusión con carácter público. La concesión se perfecciona mediante contrato escrito de concesión aprobado por resolución del titular del sector.

Como podemos apreciar, el artículo que antecede no hace restricción alguna sobre el concepto de persona jurídica. En tal sentido, cualquier persona natural (un empresario unipersonal) o persona jurídica (como sociedad anónima, sociedad de responsabilidad limitada, cooperativa, asociación o incluso fundación) tiene plena capacidad para intervenir en un contrato de concesión.

Del mismo modo, al hacer mención del concepto de "carácter público", el mismo artículo hace esta precisión para diferenciar o categorizar los servicios de telecomunicaciones conforme a la finalidad con la que se prestan (partiendo de la premisa de que todo servicio público de telecomunicaciones -salvo excepciones señaladas por ley-requiere para su prestación la previa tramitación de la concesión respectiva). En tal sentido, si el servicio de telecomunicaciones tiene por finalidad satisfacer una necesidad personal (caso de una persona natural) o una necesidad empresarial (caso de personas jurídicas), sin que el mismo sea ofertado a terceras personas, entenderemos que el servicio de telecomunicaciones tiene carácter privado, por lo que su prestación no se encontrará supeditada a la previa tramitación de una concesión (por ejemplo, las redes privadas que emplean las instituciones bancarias a fin de interconectar todas sus agencias o sucursales) ${ }^{1}$.

1 "Artículo 40,- Serán considerados servicios públicos de telecomunicaciones aquellos servicios declarados como tales en el reglamento de esta ley, que estén a
Lo contrario ocurre si, a partir del servicio de telecomunicaciones desarrollado, la persona natural o jurídica lo emplea con la finalidad de comercializarlo en el mercado peruano a cambio de una contraprestación económica. En este caso entenderemos que el servicio de telecomunicaciones provisto por esta persona tiene un carácter público (por ejemplo, la prestación de servicios de larga distancia a terceros mediante los diversos sistemas con los que se cuenta para este fin-preselección, llamada por llamada, tarjetas prepago), por lo que requerirá la previa tramitación de una concesión a fin de prestarse en el mercado peruano ${ }^{2}$.

\subsection{Clases de concesiones}

Las concesiones pueden ser otorgadas a solicitud de parte o por concurso público de ofertas, siempre y cuando (en ambos casos) el concesionario cumpla con los

disposición del público en general y cuya utilización se efectúe a cambio del pago de una contraprestación. Su prestación será normada por la presente ley y podrá ser reglamentada cuando por las características del servicio ello fuere necesario".

2 "Artículo 41- Serán considerados servicios privados de telecomunicaciones aquellos servicios que han sido establecidos por una persona natural o jurídica para satisfacer sus propias necesidades de comunicación, dentro del territorio nacional. Estos servicios no pueden ser brindados a terceros salvo que se trate del suministro de servicios de valor añadido para el cumplimiento de su objeto social. Para efectos de su clasificación como servicios privados se considerará como una misma persona a los miembros, filiales y subsidiarias de una misma persona jurídica que funcionen como un conjunto económico. Estos servicios no pueden ser brindados a terceros".

La mención de "conjunto económico" se refiere al grupo de empresas que tienen como socio principal a una misma persona natural o jurídica, la cual es titular directo o indirecto de por lo menos el $51 \%$ de las acciones, participaciones o de los derechos que otorguen el control efectivo sobre los integrantes del grupo empresarial. 
requisitos exigidos por ley, con el pago correspondiente al derecho de concesión y con el pago de la publicación de la resolución ministerial que lo otorga (art. 125 del Reglamento General de la Ley de Telecomunicaciones).

\subsubsection{Concesiones otorgadas a solicitud de parte}

El decreto supremo 002-99-MTC modificó el artículo 136 del Reglamento General de la Ley de Telecomunicaciones, relativo a la información que debe contener la solicitud que se hace para el otorgamiento de una concesión. El nuevo artículo y el novísimo Texto Único de Procedimientos Administrativos del MTC disponen que la solicitud respectiva deberá ser dirigida al Ministerio de Transportes, Comunicaciones, Vivienda y Construcción, adjuntándosele la siguiente información y documentación:

a) Para el caso de personas jurídicas:

- copia del testimonio de constitución social de la empresa,

- copia del poder vigente de su representante legal, debidamente legalizado por notario público o fedatario del Ministerio,

- datos personales de los socios o accionistas que representen el $10 \%$ o más del capital social de la empresa, con fotografías (por triplicado), y

- declaración jurada del solicitante y de los socios o accionistas con derecho a voto igual o superior al $10 \%$ del capital social de la empresa, de no hallarse impedidos de contratar con el Estado ni estar incursos en las limitaciones establecidas en la ley y el reglamento.

b) Para el caso de personas naturales:

- copia del documento de identidad legalizado por notario público o fedatario,
- datos personales del solicitante, y

- declaración jurada del solicitante,

Asimismo, tanto para las solicitudes presentadas por personas naturales como para las presentadas por personas jurídicas, se deberá adjuntar:

- un perfil del proyecto técnico para la prestación del servicio solicitado, autorizado por ingeniero colegiado de la especialidad, y

- una proyección de la inversión prevista para los primeros cinco años y monto de la inversión inicial destinada a ser ejecutada durante el primer año.

\subsubsection{Concesiones otorgadas por concurso público}

El artículo 124 del Reglamento General de la Ley de Telecomunicaciones, modificado por decreto supremo 002-99-MTC, establece los casos en que el otorgamiento de una concesión debe efectuarse mediante concurso público:

- cuando en una determinada localidad o área de servicio exista restricción a la disponibilidad de frecuencias o banda de frecuencia disponible, para la prestación de un determinado servicio público de telecomunicaciones,

- cuando se señale en el Plan Nacional de Atribución de Frecuencias, y

- cuando se restrinja (vía decreto supremo expedido por el MTC) el número de concesionarios de un determinado servicio público, al amparo del artículo 70 de la ley, debido a restricciones técnicas basadas en recursos escasos.

\subsection{Requisitos para obtener la concesión}

La obtención de la concesión de un servicio de telecomunicaciones implica de por sí la suscripción de un contrato entre 
el solicitante y el Estado peruano, donde este último autoriza al primero a explotar dicho servicio. Además, el solicitante no debe encontrarse probibido de contratar con el Estado por mandato legal o de autoridad competente (art. 126 del Reglamento General de la Ley de Telecomunicaciones).

Con respecto a las prohibiciones de contratación, la Ley de Contrataciones y Adquisiciones del Estado -ley 26850, publicada el 3 de agosto de 1997, luego modificada por ley 27330 , publicada el 26 de julio de 2000- establece las normas que deberán ser observadas por las entidades del sector público en los procesos de contrataciones y adquisiciones de bienes y servicios de toda naturaleza. En tal sentido, su artículo 9 señala quiénes se encuentran impedidos de ser postores y/o contratistas en los procesos de contrataciones y/o adquisiciones con el Estado:

Artículo 9-- Están impedidos de ser postor y/o contratista:

a) El presidente y los vicepresidentes de la República, los representantes al Congreso, los ministros de Estado, los vocales de la Corte Suprema de Justicia de la República, los titulares y los miembros de los órganos colegiados de los organismos constitucionalmente autónomos, hasta seis meses después de haber dejado el cargo.

b) Los titulares de instituciones de organismos públicos descentralizados, los alcaldes, los demás funcionarios públicos, los directores y funcionarios de las empresas del Estado, las personas naturales de la entidad que tenga intervención directa en la definición de necesidades, especificaciones, evaluación de oferta, selección de alternativas, autorización de adquisiciones o pagos.

c) El conyuge, conviviente o los parientes hasta el cuarto grado de consanguinidad y segundo de afinidad, de las personas a que se refieren los literales precedentes.

d) Las personas jurídicas en las que las personas naturales a que se refieren los lite- rales a), b) y c) tengan una participación superior al 5\% del capital social dentro de los 24 meses anteriores a la convocatoria.

e) Las personas naturales o jurídicas que se encuentren sancionadas administrativamente con inhabilitación temporal o permanente para contratar con entidades del sector público, de acuerdo a lo dispuesto por la presente ley y su reglamento.

f) La persona natural o jurídica que haya participado en la elaboración de los estudios o información técnica previa que da origen al proceso de selección y sirve de base para el objeto del contrato, salvo en los casos de los contratos de supervisión.

En los casos a que se refieren los incisos b), c) y d) el impedimento para ser postor se restringe al ámbito de la jurisdicción o sector al que pertenecen las personas a que se refieren los literales a) y b). En los casos de los organismos constitucionalmente autónomos, el impedimento se circunscribe a las adquisiciones y contrataciones que realizan dichas entidades.

Las propuestas que contravengan a lo dispuesto en el presente artículo se tendrán por no presentadas, bajo responsabilidad de los miembros del comité. Los contratos celebrados en contravención de lo dispuesto en el presente artículo son nulos, sin perjuicio de las acciones a que hubiere lugar.

\subsection{Casos señalados por ley en los cuales no se podrá otorgar la concesión}

El Reglamento de la Ley de Telecomunicaciones y sus modificatorias establecen taxativamente los casos en los cuales el Ministerio de Transportes y Comunicaciones no podrá otorgar la concesión o autorización solicitada. $\mathrm{Al}$ respecto, su artículo 116 establece lo siguiente:

Artículo 116.- El Ministerio no otorgará la concesión o autorización solicitada cuando: 
1. El otorgamiento de la concesión o autorización ponga en peligro real o potencial la seguridad nacional. Para tal efecto, el Ministerio solicitará la información que considere necesaria a las autoridades correspondientes, quienes deberán atenderla en un plazo que no excederá de sesenta (60) días calendario.

2. El solicitante no tenga la suficiente capacidad técnica o económica para ejecutar el proyecto presentado y en especial el plan de expansión de los servicios que ha solicitado, tratándose de servicios públicos.

3. Al solicitante o a alguno de los socios o asociados, tratándose de personas jurídicas, se le hubiere sancionado con la cancelación de alguna concesión o autorización del servicio de telecomunicaciones y no hayan transcurrido dos (2) años desde la fecha en que la resolución de cancelación quedó firme administrativamente. No será de aplicación esta limitación cuando la causal de cancelación fuera la falta de pago de la tasa por explotación comercial del servicio o del canon, en cuyo caso el otorgamiento de la concesión o autorización está sujeto a lo dispuesto en el artículo 117.

4. Se ponga en peligro real o potencial el cumplimiento de los fines de las telecomunicaciones como mecanismo de integración, pacificación, desarrollo y como vehículo de cultura.

5. El solicitante estuviera incurso en alguna de las prohibiciones establecidas en la ley y en el reglamento.

6. El solicitante no se encuentre al día en los pagos que resulten exigibles respecto de derechos, tasas y canon por alguna concesión o autorización que se le hubiera otorgado.

7. Al solicitante se le hubiere sancionado con multa y no haya cumplido con el pago previo de la misma, siempre que ésta resultara exigible.

8. Otras que se contemplen en la ley y en el reglamento.

\subsection{Los contratos de concesión: composición}

Previa evaluación efectuada por la Unidad de Concesiones en Telecomunicaciones del MTC (órgano encargado de dar trámite a las solicitudes de concesión formuladas por los solicitantes), que versará sobre aspectos técnicos, económicos y legales respecto de los documentos presentados por el solicitante, y de observarse que la solicitud planteada cumple con todos los requisitos de ley, se procederá a la suscripción del respectivo contrato de concesión.

Los contratos de concesión, de acuerdo con lo establecido por el artículo 118 del Reglamento de la Ley de Telecomunicaciones, deben contener, entre otros elementos: 1) las características técnicas específicas de operación de los servicios autorizados, 2) el plazo para realizar la instalación de los mismos, y 3) los sistemas que sean necesarios para la prestación del servicio. Por otro lado, al configurarse este instrumento como un acuerdo entre las partes, requiere de la redacción de diversas cláusulas legales que le permitan constituir mecanismos para su normal desenvolvimiento, como son: cláusulas de resolución y/o terminación del contrato, cláusulas de jurisdicción, cláusulas de solución de controversias, cláusulas de incumplimiento por causal, entre otras.

\subsection{Cláusulas de terminación y resolución del contrato}

De acuerdo con los modelos de contratos de concesión que vienen siendo empleados por el MTC, son admitidas dos formas o clases de conclusión del contrato de concesión.

a) Conclusión del contrato por terminación 
Esta forma de conclusión del contrato de concesión procede al configurarse cualquiera de los siguientes supuestos:

- por vencimiento del plazo de la concesión,

- por acuerdo entre las partes,

- por solicitud de la empresa concesionaria, que deberá formularla por escrito y con una anticipación de seis meses, $y$

- por declaración de insolvencia del concesionario.

b) Conclusión del contrato por resolución Esta forma de conclusión del contrato de concesión se configura de manera unilateral, cuando el MTC advierte algún incumplimiento por parte de la concesionaria al:

- no cumplir dentro de los 24 meses de suscrito el contrato con el plan mínimo de expansión,

- no cumplir con los pagos de las tasas al Fitel, Osiptel y MTC, y

- incurrir en alguna de las causales de resolución establecidas por el artículo 135 del Reglamento de la Ley de Telecomunicaciones:

Artículo 135.- El contrato de concesión se resuelve por:

- Incumplimiento del plazo pactado para iniciar la prestación del servicio. Si el contrato de concesión comprende varios servicios, la resolución opera sólo respecto al servicio cuyo plazo para iniciar su prestación se hubiera incumplido.

- Incumplimiento del pago de la tasa anual por la explotación comercial del servicio durante dos años calendarios consecutivos.

- Incumplimiento del pago del canon anual por la utilización del espectro radioeléctrico por dos años calendarios consecutivos.

- Incumplimiento de otras obligaciones contraidas por el concesionario, cuando hayan sido expresamente convenidas como causales de resolución del contrato.
- Suspensión de la prestación del servicio sin autorización del Ministerio, salvo que ésta se produzca por razones de fuerza mayor o caso fortuito debidamente acreditados y calificados como tales por el Ministerio.

Sólo en el caso de configurarse alguno de los supuestos de conclusión del contrato por resolución procedería la cancelación de la concesión para efectos de lo señalado por el artículo 116 del Reglamento (del que a continuación trataremos), en virtud de que denotarían un claro incumplimiento contractual por parte del concesionario (sancionado por eso con la cancelación de la concesión), a diferencia de los supuestos de terminación, que se configuran básicamente por situaciones de hecho, o en todo caso por situaciones acordadas por ambas partes, siendo su efecto la simple conclusión del contrato de concesión.

\subsection{Efectos legales de la cancelación de la concesión}

El principal efecto que implica la cancelación de la concesión radica en la imposibilidad del exconcesionario de poder tramitar durante los dos años siguientes a la cancelación cualquier solicitud de concesión de servicios de telecomunicaciones ante el MTC. En efecto, de acuerdo con el numeral 3 del artículo 116 del Reglamento de la Ley de Telecomunicaciones, procederá la denegación de cualquier solicitud de concesión en el caso de

... Que al solicitante o a alguno de los socios o asociados, tratándose de personas jurídicas, se le hubiere sancionado con la cancelación de alguna concesión o autorización del servicio de telecomunicaciones, y no hayan transcurrido dos (2) años desde la fecha en que la resolución de cancelación quedo firme administrativamente. 
La denegación no procederá cuando la causal de cancelación fuera la falta de pago de la tasa por explotación comercial del servicio o del canon, en cuyo caso el otorgamiento de la concesión o autorización está sujeto a lo dispuesto en el artículo 117 del reglamento de la ley.

\section{CONCLUSIONES} cluir:

A modo de resumen, podemos con-

- los servicios de telecomunicaciones pueden ser clasificados en públicos o privados, según el destino que se les quiera dar (uso privado o uso comercial);

- para su prestación, los servicios públicos requieren de la previa suscripción de un contrato de concesión (salvo los servicios de valor añadido);

- el Estado permite el acceso de personas naturales y jurídicas a las concesiones en materia de telecomunicaciones, sin realizar distinción alguna en cuanto a su forma jurídica (sociedades, asociaciones, etc.);

- los requisitos así como las causales para la no obtención de una concesión se encuentran taxativamente señalados por la ley de la materia; y

- el incumplimiento de las obligaciones a cargo del concesionario puede ser materia de resolución de contrato (y consiguiente cancelación de la concesión), con la consecuente inhabilitación del exconcesionario, durante el tiempo señalado por la ley, para solicitar una nueva concesión. 